\title{
Maternal placental syndromes among women living with HIV in Ontario: a population-based study
}

\author{
Ryan Ng MSc, Erin M. Macdonald MSc, Mark H. Yudin MD MSc, Ahmed M. Bayoumi MD MSc, \\ Mona R. Loutfy MD MPH, Janet Raboud PhD, Khatundi-Irene Masinde, Wangari E. Tharao, \\ Jason Brophy MD MSc, Richard H. Glazier MD MPH, Tony Antoniou PhD
}

\section{Abstract}

Background: Maternal placental syndromes are associated with adverse fetal outcomes and maternal cardiovascular disease. However, whether HIV infection increases the risk of maternal placental syndromes is unknown. Our objective was to compare the risk of maternal placental syndromes between women living with and without HIV infection in Ontario.

Methods: We conducted a population-based study using health administrative data from Ontario. We identified all pregnancies resulting in a live birth between Apr. 1, 2002, and Mar. 31, 2011; we identified women living with HIV using a validated case-finding algorithm. Our primary composite outcome was maternal placental syndromes, defined as a diagnosis of preeclampsia, eclampsia, placental abruption or placental infarction. We used generalized estimating equations with a logit link function to derive adjusted odds ratios (AORs) and 95\% confidence intervals $(\mathrm{Cl})$ for the association between HIV infection and maternal placental syndromes.

Results: Data from 1132871 pregnancies were available for analysis; 634 (0.06\%) of the pregnancies were in women living with HIV. After multivariable adjustment, we found no difference in the risk of maternal placental syndromes between women living with HIV and those without HIV infection (5.8\% v. 5.6\%; AOR 0.85 [95\% Cl 0.59-1.21]). An increased risk of maternal placental syndromes was associated with pre-existing diabetes (AOR 1.47 [95\% Cl 1.39-1.54]), pre-existing hypertension (AOR 4.28 [95\% Cl 4.15-4.42]) and chronic kidney disease (AOR 1.83 [95\% Cl 1.61-2.08]).

Interpretation: Women with HIV are not at increased risk of maternal placental syndromes. Our results underscore the importance of optimizing the management of comorbid illness associated with maternal placental syndromes during the prenatal period for all women, irrespective of HIV status.

\section{M} aternal placental syndromes, an inter-related group of disorders that includes preeclampsia, eclampsia, placental infarction and placental abruption, complicate $5.7 \%$ of pregnancies in Ontario. ${ }^{1}$ However, whether HIV imparts a heightened risk of maternal placental syndromes among women in Ontario is unknown. These data are important for several reasons. First, women are increasingly represented among the population of persons with $\mathrm{HIV}$ who have entered care in Ontario, comprising about 20\% of this population as of $2009 .{ }^{2}$ Moreover, $82 \%$ of these women are of child-bearing age. ${ }^{2}$ Second, maternal placental syndromes increase the risk of preterm delivery, fetal growth restriction and low-birth-weight infants, ${ }^{3}$ adverse fetal outcomes that occur with greater frequency among women with HIV. Specifically, in an earlier study, we found that the proportion of births that were preterm $(14.6 \%$ v. $6.3 \% ; p<0.001)$, small for gestational age $(14.6 \%$ v. $10.3 \% ; p<0.001)$ and low birth weight $(12.5 \%$ v. $4.6 \% ; p<0.001)$ were higher among Ontario women with than among those without HIV infection. ${ }^{4} \mathrm{~A}$ finding of a higher risk of maternal placental syndromes among women with HIV could provide insight into the cause of the higher-than-expected rates of these adverse neonatal outcomes. Finally, in addition to fetal harm, maternal placental syndromes are associated with an increased risk (about 2-fold) of premature cardiovascular disease in affected women. ${ }^{5-8}$ This association between maternal placental syndromes and future cardiovascular disease may reflect the effects of overlapping risk factors such as hypertension. ${ }^{9}$ Alternatively, some evidence suggests that maternal placental syndromes precipitate a series of vascular changes in women that increase the risk of future cardiovascular impairment. ${ }^{10-13}$ The association of maternal placental syndromes with maternal cardiovascular disease is augmented in women with pre-existing metabolic syndrome.

Competing interests: None declared.

This article has been peer reviewed.

Correspondence to: Tony Antoniou, tantoniou@smh.ca

CMAJ Open 2015. DOI:10.9778/cmajo.20140112 
In one study, the risk of future cardiovascular disease among women with maternal placental syndromes and 1 to 2 features of metabolic syndrome was increased 4-fold relative to women who had neither; this risk was increased more than 11 -fold for women with 3 or 4 components of metabolic syndrome. ${ }^{6}$ These findings are particularly concerning in the context of HIV infection, because the prevalence of metabolic syndrome is higher among women living with HIV than among those without HIV, thereby predisposing these women to both maternal placental syndromes and cardiovascular sequelae. ${ }^{14-16}$

Several studies have compared the risk of 1 or more placental disorders between women living with and without HIV, with conflicting results. ${ }^{17-23}$ A recent meta-analysis found no difference in the risk of preeclampsia between women living with and without HIV but was unable to precisely estimate the association between HIV and eclampsia (odds ratio [OR] 2.56, 95\% confidence interval [CI] $0.15-$ 44.11). ${ }^{24}$ Furthermore, with the exception of 1 large study involving a sample of $20 \%$ of all community hospitals in the United States, ${ }^{23}$ existing risk estimates have been derived from single-centre studies with small samples. Many of these studies did not account for comorbid diseases known to influence the risk of maternal placental disorders, such as hypertension, diabetes and chronic kidney disease. In addition, the existing literature reflects a time period (i.e., before 2003) that predates the widespread use of ritonavir-boosted protease inhibitor therapy among pregnant women with HIV. Because protease inhibitors may increase the risk of metabolic syndrome and are currently used by almost $80 \%$ of women living with HIV during their pregnancies, contemporary estimates of the risk of maternal placental syndromes among these women are required. ${ }^{25,26} \mathrm{We}$ performed a population-based study to compare the risk of maternal placental syndromes between women living with and without HIV infection in Ontario between Apr. 1, 2002, and Mar. 31, 2011.

\section{Methods}

\section{Data sources}

We used Ontario's administrative health databases, which were held securely in linkable files without any direct personal identifiers, and analyzed at the Institute for Clinical Evaluative Sciences (ICES). We identified all pregnancies among Ontario women between the ages of 18 and 49 years during the study period using the MOMBABY database, which deterministically links the Canadian Institute for Health Information Discharge Abstract Database inpatient admission records of all mothers and their newborn infants from fiscal year 2002/03 onward. Within this cohort, we identified births to women living with HIV using the Ontario HIV Database, an administrative data registry of Ontario residents with diagnosed HIV infection that was generated using a previously validated case-finding algorithm. ${ }^{27}$ The definition of 3 physician claims with an International Classification of Diseases, 9th revision code for HIV infection $(042,043,044)$ within a 3 -year period has a sensitivity of $96.2 \%$ (95\% CI $95.2 \%-$ $97.9 \%$ ) and a specificity of $99.6 \%$ (95\% CI $99.1 \%-99.8 \%)$ for identifying people living with $\mathrm{HIV} .{ }^{27} \mathrm{We}$ obtained demographic information from the Registered Persons Database, a registry of all Ontario residents eligible for provincial health insurance. We obtained data on hospital admissions from the Discharge Abstract Database, which contains detailed clinical information regarding all hospital admissions in Ontario. We used the Ontario Health Insurance Plan database to identify claims for physician services and pre-existing medical conditions that may influence the risk of maternal placental syndromes. We used validated disease registries to define the presence of diabetes and hypertension. ${ }^{28,29}$ We used neighbourhood instability and deprivation as measures of maternal socioeconomic status based on the 2006 Canadian Census. ${ }^{30}$ We adjusted for differences in comorbidity by calculating the number of aggregated diagnosis groups for each woman, using the John Hopkins Adjusted Clinical Group system. ${ }^{31}$ This method of case-mix adjustment has been studied among Ontario adults with HIV and found to have comparable discriminative performance for mortality and greater discriminative performance for hospital admission than other commonly used methods. ${ }^{32} \mathrm{We}$ determined the adequacy of prenatal care using the RevisedGraduated Prenatal Care Utilization Index (R-GINDEX). ${ }^{33}$ The R-GINDEX is a summary measure of prenatal care, and is calculated on the basis of the number of visits for prenatal care and the trimester care began, taking gestational age into account. Finally, because immigration status has been previously shown to be associated with maternal placental syndromes, ${ }^{1}$ we determined immigration status and world region of origin using the Citizenship and Immigration Database, and categorized time since immigration to Ontario as recent $(\leq 5 \mathrm{yr})$ or nonrecent (> 5 yr). These databases were linked in an anonymous fashion using encrypted health card numbers, and are routinely used for population-based research examining pregnancy outcomes, including maternal placental syndromes. ${ }^{1,4,34}$

We obtained supplemental data regarding antiretroviral therapy, viral load and perinatal transmission from the Canadian Perinatal HIV Surveillance Program.

This project was approved by the Research Ethics Board of Sunnybrook Health Sciences Centre, Toronto.

\section{Outcome}

Our primary composite outcome was maternal placental syndromes, defined as a diagnosis of preeclampsia, eclampsia, placental abruption or placental infarction during each hospital admission for a delivery. We determined the presence of each outcome from the maternal admission record in the MOMBABY database using the International Classification of Diseases, 10th revision coding system (Appendix 1, available at www.cmajopen.ca/content/3/4/E360/suppl/DC1).

\section{Statistical analyses}

We compared baseline characteristics of mothers living with and without HIV using a 2-sample $t$ test for continuous variables, Cochrane-Armitage tests for ordinal variables and $\chi^{2}$ tests for categorical variables. We compared the proportions of pregnancies complicated by maternal placental syndromes using multivariable generalized estimating equations with a logit link function and an 
exchangeable correlation structure to account for multiple pregnancies in the same woman during the follow-up period. We adjusted models for variables known to influence the risk of maternal placental syndromes, including age, parity, multiple versus singleton birth, maternal comorbidity, pre-existing hypertension, diabetes (pre-existing and diagnosed during pregnancy), chronic kidney disease, dyslipidemia, immigration status, adequacy of prenatal care and socioeconomic status. ${ }^{35} \mathrm{We}$ used time-updated covariates for variables that could change with time (e.g., age, presence of comorbid conditions). ${ }^{35}$ In a sensitivity analysis, we adjusted models for obesity and smoking, 2 variables that could influence the risk of maternal placental syndromes, but which are unlikely to be well captured in our databases. We used SAS version 9.3 (Cary, NC) for all analyses.

\section{Results}

We identified 1133505 pregnancies resulting in a live birth between Apr. 1, 2002, and Mar. 31, 2011, of which 634 (0.06\%) were in women living with HIV. Relative to women without $\mathrm{HIV}$, women with HIV were more likely to be immigrants to Ontario (48.1\% v. $25.8 \%$; $p<0.001)$ and have greater comorbidity, as shown by the median number of aggregated diagnosis groups in the preceding year (6 [interquartile range (IQR) 5.0$9.0]$ v. 4.0 [IQR 3.0-6.0]; $p<0.001$ ) (Table 1). However, with the exception of chronic kidney disease in the 24 months preceding pregnancy, we saw no differences in the proportions of women living with and without HIV with known risk factors for maternal placental syndromes, including pre-existing diabetes $(1.9 \%$ v. $1.8 \% ; p=0.8)$, diabetes diagnosed during pregnancy $(5.8 \%$ v. $5.0 \% ; p=0.4)$, pre-existing hypertension (3.6\% v. $2.6 \% ; p=0.1)$ and hypertension diagnosed during pregnancy $(3.5 \%$ v. $4.4 \% ; p=0.2)$.

Supplemental data regarding antiretroviral therapy, viral load and perinatal transmission were extracted for 614 births to women living with HIV in Ontario for the period covered by our study, which show that $86.5 \%$ of women with HIV received combination antiretroviral therapy during their pregnancies, and only $8.5 \%$ received no antenatal therapy (Lindy Samson, co-chair Canadian Perinatal HIV Surveillance Program, personal communication). Of the women on combination antiretroviral therapy, most (78.9\%) received protease inhibitors, and the risk of vertical transmission was $1.1 \%$. Viral load data were available for $90.9 \%$ of women during the period encompassing 2006-2011, of whom $82.8 \%$ attained virologic suppression below the limits of detection (50 copies/mL), with a further $10.3 \%$ achieving suppression to less than 1000 copies per millilitre. The timing of when the viral load was obtained relative to delivery was recorded for $36.9 \%(n=146)$ of women, with the median being 19.5 days before delivery (Canadian Perinatal HIV Surveillance Program, personal communication).

Overall, maternal placental syndrome developed in 63217 (5.6\%) women during the study. The proportions of women living with and without HIV in whom maternal placental syndromes developed during pregnancy were similar $(5.8 \% \mathrm{v}$. $5.6 \% ; p=0.8)$. After multivariable adjustment, there was no sig- nificant difference in the risk of maternal placental syndromes between women living with and without HIV infection (adjusted OR 0.85, 95\% CI 0.59-1.21) (Table 2). The results did not change in a sensitivity analysis adjusting for smoking and obesity (Appendix 2, available at www.cmajopen.ca/content/3/4/ E360/suppl/DC1). The odds of maternal placental syndrome were lower among immigrants to Ontario relative to nonimmigrants, with the lowest risk being seen among recent (i.e., $<5 \mathrm{yr}$ ) immigrants from world regions outside of Africa or the Caribbean (Table 2). The risk of maternal placental syndromes was increased among women with established risk factors for these disorders, including pre-existing diabetes (adjusted OR 1.47, 95\% CI 1.39-1.54), pre-existing hypertension (adjusted OR 4.28, 95\% CI 4.15-4.42) and chronic kidney disease (adjusted OR 1.83, 95\% CI 1.61-2.08) (Table 2).

\section{Interpretation}

We found no excess risk of maternal placental syndromes among women living with HIV relative to women without HIV infection. Our study provides a contemporary populationbased estimate of the risk of maternal placental syndromes in women living with HIV and is reflective of a period during which protease inhibitor-based antiretroviral therapy was used by most women with HIV during the prenatal period.

Our findings are in general agreement with previous studies; ${ }^{19,20,23}$ but they differ from those of a cohort study that showed a nearly five-fold increase in the risk of preeclampsia in 82 women living with HIV relative to 8686 women without HIV. ${ }^{22}$ However, that study differed from ours in several important respects, including being conducted in a single referral centre and a lack of control for important confounders in the association between $\mathrm{HIV}$-infection and preeclampsia, including diabetes, hypertension and chronic kidney disease.

\section{Strengths and limitations}

Our study is strengthened by the population-based nature of the data, which allowed us to examine more than 1 million pregnancies during the study period. However, we could not determine births that occurred outside of a hospital, which account for about $1.1 \%$ of all births in Ontario. ${ }^{36}$

We did not have reliable data on some determinants of maternal placental syndromes, including smoking and body mass index, and because we used administrative data, outcome misclassification is possible. However, differential outcome misclassification is unlikely, because maternal placental syndromes are recorded for all women at the time of delivery in mandatory fields of the Ontario birth record by the attending physician or midwife. In addition, although we adjusted for region of origin, residual confounding related to race was possible.

Finally, our databases do not include clinical information or reliable estimates of antiretroviral drug use. Although we were not able to capture CD4+ count at delivery, data from the Canadian Perinatal HIV Surveillance Program suggest that most women were receiving antiretroviral therapy, had achieved virologic suppression and were therefore appropriately managed in terms of their HIV infection. 
Table 1: Baseline characteristics of included patients, by HIV status

\begin{tabular}{|c|c|c|c|}
\hline Characteristic & $\begin{array}{c}\text { HIV, no. }(\%)^{*} \\
n=634\end{array}$ & $\begin{array}{c}\text { Non-HIV, no. }(\%)^{*} \\
n=1132871\end{array}$ & $p$ value \\
\hline Age, yr, mean \pm SD & $30.8 \pm 5.2$ & $30.1 \pm 5.2$ & 0.002 \\
\hline $18-34 \mathrm{yr}$ & $470(74.1)$ & $895675(79.1)$ & 0.002 \\
\hline $35-49 \mathrm{yr}$ & $164(25.9)$ & $237196(20.9)$ & \\
\hline \multicolumn{4}{|l|}{ Aggregated diagnosis groups } \\
\hline Median (IQR) & $6.0(5.0-9.0)$ & $4.0(3.0-6.0)$ & $<0.001$ \\
\hline Pre-existing diabetes & $12(1.9)$ & $20211(1.8)$ & 0.8 \\
\hline Diabetes diagnosed during pregnancy & $37(5.8)$ & $57007(5.0)$ & 0.4 \\
\hline Pre-existing hypertension & $23(3.6)$ & $29789(2.6)$ & 0.1 \\
\hline $\begin{array}{l}\text { Hypertension diagnosed during } \\
\text { pregnancy }\end{array}$ & $22(3.5)$ & $50192(4.4)$ & 0.2 \\
\hline Hyperlipidemia & $19(3.0)$ & $25984(2.3)$ & 0.2 \\
\hline Obesity & $17(2.7)$ & $30659(2.7)$ & 1.0 \\
\hline Chronic kidney disease & $8(1.3)$ & $2046(0.2)$ & $<0.001$ \\
\hline Adequacy of prenatal care (R-GINDEX) & & & $<0.001$ \\
\hline Adequate & $175(27.6)$ & 428867 (37.9) & \\
\hline Intensive & $54(8.5)$ & $61597(5.4)$ & \\
\hline Intermediate & $304(47.9)$ & $484055(42.7)$ & \\
\hline Inadequate & $101(15.9)$ & $156982(13.9)$ & \\
\hline Immigration status, region of origin & & & $<0.001$ \\
\hline Non-immigrant & $329(51.9)$ & $840609(74.2)$ & \\
\hline $\begin{array}{l}\text { Non-recent immigrant, Africa } \\
\text { or Caribbean }\end{array}$ & $97(15.3)$ & $23814(2.1)$ & \\
\hline $\begin{array}{l}\text { Non-recent immigrant, other world } \\
\text { regions }\end{array}$ & $28(4.4)$ & $108480(9.6)$ & \\
\hline Recent immigrant, Africa or Caribbean & $157(24.8)$ & $15412(1.4)$ & \\
\hline Recent immigrant, other world regions & $23(3.6)$ & $144556(12.8)$ & \\
\hline Material deprivation income quintile & & & $<0.001$ \\
\hline 1 (least deprived) & $68(10.7)$ & $296868(26.2)$ & \\
\hline 2 & $72(11.4)$ & $233052(20.6)$ & \\
\hline 3 & $98(15.5)$ & $213667(18.9)$ & \\
\hline 4 & $117(18.5)$ & $190959(16.9)$ & \\
\hline 5 (most deprived) & $261(41.2)$ & $183836(16.2)$ & \\
\hline Residential instability quintile & & & $<0.001$ \\
\hline 1 (least instability) & $77(12.1)$ & $303577(26.8)$ & \\
\hline 2 & $72(11.4)$ & $228844(20.2)$ & \\
\hline 3 & $69(10.9)$ & $168458(14.9)$ & \\
\hline 4 & $145(22.9)$ & $214871(19.0)$ & \\
\hline 5 (most instability) & $253(39.9)$ & 202632 (17.9) & \\
\hline Multiple birth & $19(3.0)$ & 19849 (1.8) & 0.02 \\
\hline Preterm birth & $100(15.8)$ & $81047(7.2)$ & $<0.001$ \\
\hline \multirow[t]{2}{*}{ Previous preterm birth $\dagger$} & $n=168$ & $n=338276$ & $<0.001$ \\
\hline & $34(20.2)$ & $24912(7.4)$ & \\
\hline
\end{tabular}




\section{OPEN}

Research

\begin{tabular}{|c|c|c|}
\hline Covariate & OR $(95 \% \mathrm{Cl})$ & Adjusted OR $(95 \% \mathrm{Cl})^{*}$ \\
\hline HIV-infection & $1.02(0.72-1.45)$ & $0.85(0.59-1.21)$ \\
\hline \multicolumn{3}{|l|}{ Age, yr } \\
\hline 18-34 (reference) & 1.00 & 1.00 \\
\hline $35-49$ & $0.83(0.82-0.85)$ & $0.91(0.89-0.93)$ \\
\hline Pre-existing diabetes & $2.05(1.95-2.14)$ & $1.47(1.39-1.54)$ \\
\hline Diabetes diagnosed during pregnancy & $1.47(1.42-1.51)$ & $1.27(1.23-1.31)$ \\
\hline Pre-existing hypertension & $5.15(5.01-5.32)$ & $4.28(4.15-4.42)$ \\
\hline Hyperlipidemia & $1.27(1.21-1.33)$ & $1.03(0.98-1.08)$ \\
\hline Chronic kidney disease & $3.78(3.37-4.25)$ & $1.83(1.61-2.08)$ \\
\hline \multicolumn{3}{|l|}{ Aggregated diagnosis groups } \\
\hline 0-5 (reference) & 1.00 & 1.00 \\
\hline $6-10$ & $1.60(1.57-1.62)$ & $1.41(1.38$ t0 1.43) \\
\hline 11 or more & $2.65(2.52-2.79)$ & $1.93(1.82-2.03)$ \\
\hline \multicolumn{3}{|l|}{ Adequacy of prenatal care (R-GINDEX) } \\
\hline Adequate or intensive (reference) & 1.00 & 1.00 \\
\hline Intermediate & $0.58(0.57-0.59)$ & $0.65(0.64-0.66)$ \\
\hline Inadequate & $0.60(0.58-0.61)$ & $0.70(0.68-0.72)$ \\
\hline \multicolumn{3}{|l|}{ Immigration status } \\
\hline Non-immigrant (reference) & 1.00 & 1.00 \\
\hline Non-recent immigrant, Africa or Caribbean & $1.00(0.95-1.06)$ & $0.90(0.85-0.95)$ \\
\hline Non-recent immigrant, other world regions & $0.72(0.69-0.74)$ & $0.70(0.68-0.72)$ \\
\hline Recent immigrant, Africa or Caribbean & $0.83(0.77-0.89)$ & $0.79(0.73-0.85)$ \\
\hline Recent immigrant, other world regions & $0.63(0.61-0.64)$ & $0.64(0.62-0.66)$ \\
\hline \multicolumn{3}{|l|}{ Material deprivation income quintile } \\
\hline 1 (least deprived; reference) & 1.00 & 1.00 \\
\hline 2 & $1.02(1.00-1.05)$ & $1.04(1.01-1.06)$ \\
\hline 3 & $1.00(0.97-1.02)$ & $1.03(1.00-1.05)$ \\
\hline 4 & $1.01(0.99-1.04)$ & $1.06(1.03-1.09)$ \\
\hline 5 (most deprived) & $1.00(0.97-1.02)$ & $1.06(1.03-1.09)$ \\
\hline \multicolumn{3}{|l|}{ Residential instability quintile } \\
\hline 1 (least instability; reference) & 1.00 & 1.00 \\
\hline 2 & $1.09(1.07-1.12)$ & $1.09(1.06-1.11)$ \\
\hline 3 & $1.11(1.09-1.14)$ & $1.09(1.06-1.13)$ \\
\hline 4 & $1.07(1.05-1.10)$ & $1.07(1.04-1.10)$ \\
\hline 5 (most instability) & $1.03(1.01-1.06)$ & $1.04(1.01-1.07)$ \\
\hline Multiple birth & $2.45(2.34-2.55)$ & $2.06(1.97-2.15)$ \\
\hline Parity & $0.62(0.61-0.63)$ & $0.61(0.60-0.62)$ \\
\hline
\end{tabular}

\section{Conclusion}

Our population-based study suggests that HIV is not associated with an increased risk of maternal placental syndromes. In contrast, diabetes, hypertension and chronic kidney disease impart a substantial increase in the risk of these syndromes. Our data reinforce the importance of optimizing the management of these comorbid conditions during the prenatal period for all women, irrespective of HIV status.

\section{References}

1. Ray JG, Vermeulen MJ, Schull MJ, et al. Results of the Recent Immigrant Pregnancy and Perinatal Long-term Evaluation Study (RIPPLES). CMAf 2007;176:1419-26. 
2. Antoniou T, Zagorski B, Bayoumi AM, et al. Trends in HIV prevalence, new diagnoses and mortality in Ontario, 1996 to 2009: a population-based study. Open Med 2013;7:e98-106.

3. Scantlebury DC, Hayes SN, Garovic VD. Pre-eclampsia and maternal placental syndromes: an indicator or cause of long-term cardiovascular disease? Heart 2012;98:1109-11.

4. Macdonald EM, Ng R, Bayoumi AM, et al. Adverse neonatal outcomes among women with HIV: a population-based study. 7 Obstet Gynaecol Can 2015;37:302-9.

5. Ray JG, Vermeulen MJ, Schull MJ, et al. Cardiovascular health after maternal placental syndromes (CHAMPS): population-based retrospective cohort study. Lancet 2005;366:1797-803.

6. Wilson BJ, Watson MS, Prescott GJ, et al. Hypertensive diseases of pregnancy and risk of hypertension and stroke in later life: results from cohort study. BM7 2003;326:845.

7. Kestenbaum B, Seliger SL, Easterling TR, et al. Cardiovascular and thromboembolic events following hypertensive pregnancy. Am 7 Kidney Dis 2003;42:982-9.

8. Ray JG, Schull MJ, Kingdom JC, et al. Heart failure and dysrhythmias after maternal placental syndromes: HAD MPS Study. Heart 2012;98:1136-41.

9. Garovic VD, Hayman SR. Hypertension in pregnancy: an emerging risk factor for cardiovascular disease. Nat Clin Pract Nephrol 2007;3:613-22.

10. Melchiorre K, Sutherland GR, Baltabaeva A, et al. Maternal cardiac dysfunction and remodeling in women with preeclampsia at term. Hypertension 2011; 57:85-93.

11. Melchiorre K, Sutherland GR, Liberati M, et al. Preeclampsia is associated with persistent postpartum cardiovascular impairment. Hypertension 2011; 58:709-15.

12. Zandstra M, Stekkinger E, van der Vlugt MJ, et al. Cardiac diastolic dysfunction and metabolic syndrome in young women after placental syndrome. Obstet Gynecol 2010;115:101-8.

13. Chambers JC, Fusi L, Malik IS, et al. Association of maternal endothelial dysfunction with preeclampsia. 7AMA 2001;285:1607-12.

14. Sobieszczyk ME, Hoover DR, Anastos K, et al. Prevalence and predictors of metabolic syndrome among HIV-infected and HIV-uninfected women in the Women's Interagency HIV Study. 7 Acquir Immune Defic Syndr 2008;48: 272-80.

15. Dolan SE, Hadigan C, Killilea KM, et al. Increased cardiovascular disease risk indices in HIV-infected women. 7 Acquir Immune Defic Syndr 2005;39:44-54.

16. Johnsen S, Dolan SE, Fitch KV, et al. Carotid intimal medial thickness in human immunodeficiency virus-infected women: effects of protease inhibitor use, cardiac risk factors and the metabolic syndrome. 7 Clin Endocrinol Metab 2006;91:4916-24.

17. Boyajian T, Shah PS, Murphy KE. Risk of preeclampsia in HIV-positive pregnant women receiving HAART: a matched cohort study. 7 Obstet Gynaecol Can 2012;34:136-41.

18. Wimalasundera RC, Larbalestier N, Smith JH, et al. Pre-eclampsia, antiretroviral therapy, and immune reconstitution. Lancet 2002;360:1152-4.

19. Boer K, Nellen J, Patel D, et al. The AmRo Study: pregnancy outcome in HIV-1 infected women under effective highly active antiretroviral therapy and a policy of vaginal delivery. B7OG 2007;114:148-55.

20. Haeri S, Shauer M, Dale M, et al. Obstetric and newborn infant outcomes in human immunodeficiency virus-infected women who receive highly active antiretroviral therapy. Am 7 Obstet Gynecol 2009;201:315.e1-e5.

21. Mattar R, Amed AM, Lindsey PC, et al. Preeclampsia and HIV infection. Eur 7 Obstet Gynecol Reprod Biol 2004;117:240-1.

22. Suy A, Martínez E, Coll O, et al. Increased risk of pre-eclampsia and fetal death in HIV-infected pregnant women receiving highly active antiretroviral therapy. AIDS 2006;20:59-66.

23. Kourtis AP, Bansil P, McPheeters M, et al. Hospitalizations of pregnant $\mathrm{HIV}$-infected women in the USA prior to and during the era of HAART, 1994-2003. AIDS 2006;20:1823-31.

24. Calvert C, Ronsmans C. HIV and the risk of direct obstetric complications: a systematic review and meta-analysis. PLoS ONE 2013;8:e74848.

25. Tsiodras S, Mantzoros C, Hammer S, et al. Effects of protease inhibitors on hyperglycemia, hyperlipidemia and lipodystrophy: a 5-year cohort study. Arch Intern Med 2000;160:2050-6.

26. Griner R, Williams PL, Read JS, et al. In utero and postnatal exposure to antiretrovirals among HIV-exposed but uninfected children in the United States. AIDS Patient Care STDS 2011;25:385-94.

27. Antoniou T, Zagorski B, Loutfy MR, et al. Validation of case-finding algorithms derived from administrative data for identifying adults living with human immunodeficiency virus infection. PLoS ONE 2011;6:e21748.

28. Hux JE, Ivis F, Flintoft V, et al. Diabetes in Ontario: determination of prevalence and incidence using a validated administrative data algorithm. Diabetes Care 2002;25:512-6.

29. Tu K, Campbell NR, Chen ZL, et al. Accuracy of administrative databases in identifying patients with hypertension. Open Med 2007;1:e18-26.
30. Matheson FI, Dunn JR, Smith KLW, et al. Development of the Canadian Marginalization Index: a new tool for the study of inequality. Can 7 Public Health 2012;103(Suppl 2):S12-6.

31. Johns Hopkins ACG. Case-Mix Adjustment System. Baltimore: Johns Hopkins University. Available: http://ach.jhsph.org (accessed 2015 Sept. 15)

32. Antoniou T, Ng R, Glazier RH, et al. Comparison of comorbidity classification methods for predicting outcomes in a population-based cohort of adults with HIV infection. Ann Epidemiol 2014;24:532-7.

33. Alexander GR, Kotelchuck M. Quantifying the adequacy of prenatal care: a comparison of indices. Public Health Rep 1996;111:408-18

34. Vigod SN, Kurdyak PA, Dennis CL, et al. Maternal and newborn outcomes among women with schizophrenia: a retrospective population-based cohort study. BFOG 2014;121:566-74

35. Duckitt K, Harrington D. Risk factors for pre-eclampsia at antenatal booking: systematic review of controlled trials. BM7 2005;330:565

36. Too early, too small: a profile of small babies across Canada. Ottawa: Canadian Institute for Health Information; 2009.

Affiliations: Institute for Clinical Evaluative Sciences ( $\mathrm{Ng}$, Macdonald Loutfy, Raboud, Glazier, Antoniou); Li Ka Shing Knowledge Institute (Yudin, Antoniou, Bayoumi), St. Michael's Hospital; Centre for Research on Inner City Health (Yudin, Bayoumi), St. Michael's Hospital; Department of Obstetrics and Gynecology (Yudin), St. Michael's Hospital and University of Toronto; Department of Medicine (Loutfy, Bayoumi), University of Toronto; Women's College Research Institute (Loutfy, Masinde), Women's College Hospital; Toronto General Research Institute (Raboud), University Health Network; Dalla Lana School of Public Health (Raboud), University of Toronto; Women's Health in Women's Hands Community Health Centre (Tharao), Toronto, Ont.; Children's Hospital of Eastern Ontario and University of Ottawa (Brophy), Ottawa, Ont.; Department of Family and Community Medicine (Glazier, Antoniou), St. Michael's Hospital and University of Toronto, Toronto, Ont.

Contributors: All authors contributed to the concept and design of the study. Tony Antoniou, Ryan Ng and Erin Macdonald acquired the data, and all of the authors were involved in the analysis and interpretation of the data. Ryan $\mathrm{Ng}$ and Tony Antoniou drafted the manuscript, and all of the authors were involved in critical revision of the manuscript. All of the authors approved the manuscript submitted for publication and agree to act as guarantor for the study.

Funding: This project was supported by a research operating grant from the Ontario HIV Treatment Network and by the Institute for Clinical Evaluative Sciences (ICES), which is funded by an annual grant from the Ontario Ministry of Health and Long-Term Care (MOHLTC). The sponsors had no role in the design or conduct of the study; in the collection, analysis or interpretation of the data; or in the preparation, review or approval of the manuscript. Tony Antoniou is supported by a New Investigator Award from the Canadian Institutes for Health Research (CIHR) - Ontario HIV Treatment Network. Mona Loutfy is the recipient of salary support from Women's College Hospital, the University of Toronto and the Women's College Research Institute. Ahmed Bayoumi was supported by a CIHR - MOHLTC Applied Chair in Health Services and Policy Research. Janet Raboud is supported by an Ontario HIV Treatment Network Chair in Biostatistics and the Skate the Dream Fund, Toronto and Western Hospital Foundation.

Disclaimer: This study was supported by the Institute for Clinical Evaluative Sciences (ICES), which is funded by an annual grant from the Ontario Ministry of Health and Long-Term Care (MOHLTC). The opinions, results and conclusions reported in this paper are those of the authors and are independent from the funding sources. No endorsement by ICES or the Ontario MOHLTC is intended or should be inferred.

Acknowledgements: The authors thank the investigators of the Canadian Perinatal HIV Surveillance Program for providing data regarding antiretroviral therapy and risk of vertical transmission for mother-infant pairs in Ontario.

Supplemental information: For reviewer comments and the original submission of this manuscript, please see www.cmajopen.ca/content/3/4/ E360/suppl/DC1 